\title{
Self-Regulation versus Habit: The Influence of Self-Schema on Fruit and Vegetable Consumption
}

The aim of the current study is to examine the determinants of fruit and vegetable $(\mathrm{F} \& \mathrm{~V})$ consumption with the application of the Theory of Planned Behaviour (TPB) and the additional variables of self-schema, habit and self-regulation. While it has been shown that those with a healthy eater self-schema are more likely to carry out their healthy dietary intentions, the underlying processes that influence this relationship have received limited empirical attention. Recent findings on dietary behaviour suggest that self-regulatory ability and habit strength may have dissimilar effects on the intention-behaviour relationship within schematics and nonschematics. Self-report questionnaires regarding F\&V consumption cognitions and two tests of self-regulation were administered to 209 university students. One week later, participants completed questionnaires on their behaviour. The TPB significantly predicted intentions and prospective behaviour. Self-schema did not moderate the relationship between intention and behaviour. However, within healthy eater schematics, those with high intention and high self-regulatory ability were more likely to consume $\mathrm{F} \& \mathrm{~V}$, while within non-schematics, those with low intention and high habit strength were more likely to consume $F \& V$. The findings support the use of the TPB in predicting F\&V consumption and the validity of the self-schema distinction. Implications for designing interventions are discussed.

Keywords: Theory of planned behaviour, fruit and vegetable consumption, selfschema, executive function, self-regulation, habit 


\section{Introduction}

The consumption of fruit and vegetables $(\mathrm{F} \& \mathrm{~V})$ has been associated with a variety of physical benefits including the prevention of obesity, cardiovascular disease and cancer (Van Duyn \& Pivonka, 2000). The National Health Medical Research Council (NHMRC) recommends that Australians consume two servings of fruit and five servings of vegetables each day (NHMRC, 2003). Although the benefits associated with eating F\&V are commonly known, many individuals do not adhere to these recommendations (Australian Bureau of Statistics; ABS, 2009). The 2007-2008 National Health Survey revealed that $44 \%$ of females and $54 \%$ of males aged 15 years and over failed to meet the recommended daily intake for fruit, while $90 \%$ of females and $93 \%$ of males did not meet the recommended daily intake for vegetables.

\section{Theory of Planned Behaviour (TPB)}

The TPB primarily states that the likelihood of someone engaging in a particular behaviour can be predicted by their intention to perform that behaviour (Ajzen, 1991). The TPB has been empirically tested in many domains including dietary behaviours such as F\&V consumption (de Bruijn et al., 2007) and breakfast consumption (Wong \& Mullan, 2009). In a meta-analysis including 185 independent studies on the predictive potential of the TPB for a variety of health-related behaviours, the TPB explained $39 \%$ of the variance in intention and only $27 \%$ in behaviour (Armitage \& Conner, 2001). These findings indicate that the relationship between intention and behaviour is not uniform or consistent. Rather, a theoretical 'gap' exists between intention and behaviour where behaviour may be better predicted by factors not captured in the TPB.

\section{Self-schema}

One such factor evidenced to be a powerful regulator of behaviour is self-knowledge; awareness of one's thoughts, desires and behaviours (Markus, 1977). Compounds of selfknowledge cognitions, which are specific to one domain, are referred to as self-schemas. 
Self-schemas provide organisation and coherence to the individual's self-related experiences and therefore assist in making judgements, inferences, and decisions regarding the self. A schematic will show greater sensitivity to and preference for information applicable to their schema (Bargh, 1982) and are more inclined to behave in a schema-relevant manner (Kendzierski \& Whitaker, 1997). An individual may be classed as a schematic in a particular domain if they perceive a certain behaviour or attitude to be relevant to their self-image. In the domain of dietary behaviour, a healthy eater schematic will consider healthy eating to be both important to their self-image and self-descriptive.

In terms of the TPB, researchers have shown that the relationship between intention and behaviour is stronger for schematics than non-schematics (Kendzierski \& Costello, 2004; Sheeran \& Orbell, 2000). Kendzierski and Whitaker (1997) conducted a longitudinal study which examined the dieter self-schema of 67 female college students in relation to past dieting experience, intention, and current behaviour. It was found that schematics showed stronger and more consistent correlations between their intentions and behaviours even when past behaviour was accounted for.

Several explanations have been put forth as to why having a self-schema moderates the relationship between intentions and behaviour. For example, Stein (1995) suggested that schematics carry out schema-relevant intentions in order to verify their selfimage. Similarly, Chatzisarantis, Hagger and Wang (2008) proposed that schematics execute their intentions in order to avoid cognitive dissonance (Festinger, 1957). Finally, Cross and Markus (1990) suggested that schematics may have a greater degree of action control allowing for superior translation of intention into action.

\section{Self-regulation}

The construct of action control is theoretically similar to self-regulation (Baumeister, Schmeichel, \& Vohs, 2007). This refers to the capacity to exert control over cognition and emotion in order to organise and direct thinking towards enacting an intended 
behaviour. The biological efficiency that underlies self-regulatory capacity is thought to be executive function, which comprises higher order control processes including selective attention, planning, cognitive inhibition and flexibility of thought (Suchy, 2009). Recently, within the TPB literature, much emphasis has been placed on the role of self-regulatory ability (Hall \& Fong, 2007). Researchers have theorised that all of the aforementioned processes are prerequisites for efficient performance of intentions. Further, individual differences in self-regulatory processes can predict whether intention is translated into action (Hall, Fong, Epp, \& Elias, 2008). Given that self-regulation facilitates the translation of intention into action and that schematics are more likely to carry out their intentions, it is possible that the behaviour of schematics is a result of superior selfregulatory ability and that the influence of self-regulation in intention-behaviour translation will differ according to whether one has a relevant self-schema.

Hall, et al. (2008) examined the role of self-regulation as an additional variable to the TPB finding that cognitive inhibition explained a significant proportion of the variance in exercise and diet behaviour in addition to that explained by intentions. Further, individual differences in this self-regulation process predicted behaviour such that those with a greater ability to inhibit their responses were more inclined to carry out their intentions. Cognitive inhibition is important in dietary behaviours as low cognitive inhibition would lead to unrestrained behavioural responses that may contradict dietary intentions, for example; consuming chocolate when attempting to lose weight.

In addition to cognitive inhibition, cognitive flexibility is hypothesised to have an influence on the performance of certain behaviours (Suchy, 2009). Cognitive flexibility refers to the ability to adapt behavioural responses according to the context of the situation (Spiro, Feltovich, Jacobson, \& Coulson, 1992). Flexibility of thought may facilitate goal achievement by generating several different ways of realising intentions as well as providing alternative solutions to problems that may arise (Sniehotta, Scholz, \& 
Schwarzer, 2006). For dietary behaviour cognitive flexibility may be needed to facilitate the evaluation of food choices, adjust one's concept of what one's normal diet now entails and detect and compensate for dietary slips in order to maintain progress towards the goal.

Another self-regulatory process relevant to dietary behaviour is planning. Eating healthily requires a significant amount of planning in order to both decide which foods to avoid and then to purchase and prepare the appropriate foods before consumption. In health psychology, planning is usually conceptualised as an intervention strategy where individuals may be given structured plans or 'implementation intentions' which specify how to act if a certain situation arises (Gollwitzer, 1999). Alternatively, planning can be conceptualised as a measurable ability (Shallice, 1982). Wong and Mullan (2009) explored the role of planning in breakfast consumption and found that planning ability explained unique variance in behaviour. Given that healthy-eater schematics have been shown to carry out their healthy dietary intentions more successfully than non-schematics and that these self-regulatory processes are involved in healthy dietary behavior, it may be the case that schematics have a superior self-regulatory ability which is the underlying process responsible for the moderating effect of sel-schema on the translation of intention into behaviour.

\section{Habit}

In addition to self-regulatory ability, theorists have included the role of past behaviour or habit as an important predictor of future behaviour (Danner, Aarts, \& de Vries, 2008; Hall \& Fong, 2007). Habits are created when a particular behaviour is employed frequently and consistently in a similar situation for the same purpose (Verplanken \& Orbell, 2003). This is particularly relevant to $\mathrm{F} \& \mathrm{~V}$ consumption as dietary behaviour is repeated frequently which may result in a mental representation of the behaviour being automatically triggered within a given context without the need for conscious awareness or intent. In the domain of travel mode choice Verplanken, Aarts, van Knippenberg, and Moonen (1998) found an 
interaction between habit and intention such that intentions were only significantly related to behaviour when habit strength was weak. When participants possessed moderate or strong habits, their intentions had little influence on their subsequent behaviour. Given that dietary behaviour is a repeated activity, habit may play an important role in $\mathrm{F} \& \mathrm{~V}$ consumption. It may be the case that once a schematic forms the intention to eat $\mathrm{F} \& \mathrm{~V}$ their previous experience with this behaviour allows superior translation of intention into action. Further, as past behaviour is involved in the development of a self-schema (Kendzierski \& Whitaker, 1997) as well as a habit (Ouellette \& Wood, 1998), the role of habit in the translation of intention into behaviour for $F \& V$ consumption may differ according to whether one has a relevant self-schema.

The purpose of the present research is to use the TPB to explore the factors which influence healthy eating practices. The first aim of the study is to examine self-schema as a moderator of intention and behaviour in the domain of $\mathrm{F} \& \mathrm{~V}$ consumption. Although having a self-schema has been shown to moderate the relationship between intention and behaviour, the underlying processes that influence this relationship have received limited empirical attention. Accordingly, the second aim of the present research is to determine why having a self-schema facilitates the translation of intention into action. Previous research on the role of self-regulatory ability (Hall, et al., 2008) and habit (de Bruijn, et al., 2007) on the TPB constructs indicate that these variables can account for additional variance in behaviour and may provide insight into the possible underlying processes that are responsible for the superior ability of schematics to translate intention into action. Considering that self-regulation is not involved in habitual behaviour (Suchy, 2009), these two processes will be compared in schematics and non-schematics in order to determine their influence on the intention-behaviour relationship. Finally, given that past behaviour has been shown to be involved in the formation of both self-schemas and habits, past 
behaviour will be controlled for in order to accurately assess the role of these variables in intention-behaviour translation.

Based on the tenets of the TPB and the research discussed previously, it is hypothesised that schematics and non-schematics will differ on TPB, self-regulation and habit variables. Secondly, healthy eater self-schema will account for a significant amount of additional variance in F\&V consumption. Thirdly, healthy eater self-schema will moderate the intention-behaviour relationship such that healthy eater schematics will be more likely to carry out their F\&V consumption intentions. Finally, the influence of selfregulation and habit on the 'intention-behaviour gap' will differ according to whether one has a healthy eater self-schema or not. These effects are expected to occur over and above past behaviour.

\section{Method}

\section{Participants}

The sample consisted of 218 undergraduate students from an Australian university. After two measurement points of data collection the attrition rate was $4.1 \%$ leaving a total of 209 participants. The mean age was 20.06 years $(S D=4.39)$, ranging from 16 to 45 years. The participants were recruited using the online registration system SONA and received course credit for participation. The University Human Research Ethics Committee approved the study.

\section{Procedure}

The study employed a prospective design taking part in two sections. The first was conducted in university computer labs and involved participants completing a questionnaire containing the TPB variables, the Healthy Eater Self-Schema Scale and the Self-Report Habit Index (SRHI), as well as two computer tasks; the Iowa Gambling Task (IGT) and the Tower of Hanoi (TOH). The questionnaire was administered using open source questionnaires software: LimeSurvey, while the computer tasks were conducted 
using Inquisit 3 software. All responses were de-identified by assigning each participant a unique number. This section took approximately 25 minutes.

At the beginning of the questionnaire the participants were informed that a 'healthy eater' referred to someone who consumed the recommended daily F\&V intake. This was also specified as two serves of fruit and five serves of vegetables each day, where a serving of fruit constitutes 150 grams, equivalent to one medium piece or two small pieces of fruit while a serving of vegetables constitutes 75 grams, equivalent to half a cup of cooked vegetables or one cup of salad vegetables (NHMRC, 2003).

One week later Part 2 was emailed to participants who were required to complete the Block brief food frequency questionnaire (Block, Gillespie, Rosenbaum, \& Jenson, 2000) which measured F\&V consumption over the previous week. Part 2 took approximately five minutes.

\section{Measures}

Intention, past behaviour and behaviour

Intention was assessed through four items on a 7-point Likert scale $(1=$ strongly disagree, 7 = strongly agree), that were based on TPB guidelines (Ajzen, 2002), e.g., 'I intend to eat the recommended daily F\&V over the next week.' The four items had a Cronbach's alpha of .94 .

Past Behaviour was calculated from a single item which required participants to indicate the number of days over the past week they ate the recommended $\mathrm{F} \& \mathrm{~V}$.

Behaviour was assessed at a one week follow up using the Block brief food frequency questionnaire validated by Block, Gillespie, Rosenbaum and Jenson (2000) and shown to have adequate reliability in comparison to the full 100-item questionnaire $(r=0.71)$. Participants were asked to indicate how often they had eaten a list of seven F\&V items over the past week on a 6-point response scale ranging from $0=$ less than one serving a week, to $5=$ two or more servings a day. Responses were coded according to the screener 
guidelines and the mean daily servings were calculated using the validated formula provided by Block et al. (2000): $-0.23+0.37$ (fruit juice + fruit + vegetable juice + green salad + potatoes + vegetable soup + other vegetables $)-0.55 S$, where $\mathrm{S}=$ gender $($ Male $=$ 0 , Female $=1$ ). The formula takes into account the role of gender where men commonly underestimate the amount of F\&V they have consumed (Block et al., 1986; Subar et al., 2001). The seven items had a Cronbach's alpha of .65.

\section{Healthy eater self-schema scale}

The self-schema scale, developed by Kendzierski (1988) was used to measure healthy eater self-schema. Participants were required to rate on an 11 point scale how descriptive three statements were of themselves $(1=$ not at all descriptive, $11=$ very descriptive $)$. The participants then indicated how important they found these descriptions of themselves to be on another 11 point scale $(1=$ not at all important, $11=$ very important $)$. The three statements used for the importance and descriptiveness subscales were taken from previous studies examining self-schema and dietary behaviour (Kendzierski \& Costello, 2004). The statements included: 'I am a healthy eater,' 'I eat in a nutritious manner,' and 'I am careful about what I eat.' The three descriptiveness items had a Cronbach's alpha of .89 , while the three importance items had a Cronbach's alpha of .89 .

\section{Self-regulatory ability}

The Iowa Gambling Task (IGT), a computer simulated card game originally developed by Bechara et al. (1997), was employed to assess cognitive flexibility and cognitive inhibition. This task requires cognitive flexibility as participants must evaluate, toward a specific goal, the relative contributions of rewards and punishments in a series of risky gambling situations. The task also requires cognitive inhibition as participants must resist selecting cards with large payouts, as this will eventually lead to a greater loss. In this task participants were given the goal to win as much money as possible and were then presented with a set amount of play money (\$2000) and four decks of cards. Participants 
were required to place bets on one of the four decks of cards that each resulted in differing degrees of losses or gains. Two of the decks had large winning amounts, but also large losses, while the other two decks had smaller winning amounts, but also smaller losses. Thus the first two decks were disadvantageous because they cost the most in the long run, while the other decks were advantageous because they resulted in an overall gain in the long run. The task consisted of 50 trials. Self-regulatory ability was determined by the final amount of money a participant was left with.

The Tower of Hanoi (TOH) task, based on the Tower of Hanoi-revised (Welsh \& Huizinga, 2001) and the Tower of London (Shallice, 1982), was used to assess planning ability as this task is most efficiently completed when participants spend time planning their moves prior to commencement. The TOH consists of three disks of graduated size, stacked from largest to smallest on one of three vertical pegs. Participants were instructed to move the disks, one at a time, from the starting peg (left) to the farthest peg (right) in as few moves as possible, with no larger disk being able to be stacked upon any smaller disk. The measures of interest were preplanning time: the amount of time in seconds from the appearance of the disks to the first move made and number of errors: the number of moves made minus the minimum number of moves necessary to solve the task. The minimum move requirement was seven, which has been shown to be adequately challenging, while solvable in a reasonable amount of time (Humes, Welsh, Retzlaff, \& Cookson, 1997). Self Report Habit Index (SRHI) In order to assess the extent to which F\&V consumption was habitual, the SRHI (Verplanken \& Orbell, 2003) was employed. Participants responded to the stem "Eating the recommended daily F\&V is something...," which was followed by the 12 items of the scale designed to measure intentionality, controllability, awareness and mental efficiency. Three sample items are "I do automatically," "that belongs to my daily routine," and "I 
would find hard not to do." Responses were given on 7-point Likert Scales $(1=$ strongly disagree, $7=$ strongly agree). The 12 items had a Cronbach's alpha of .96 .

\section{Analysis}

Data was analysed using the SPSS 17.0 for Windows software package. Correlation and multiple regression analyses were conducted to test the research hypotheses. Responses on the healthy eater self-schema scale formed a continuous variable which was used to test the moderating effect on intention and behaviour. In order to assess the role of selfregulation and habit within schematics and non-schematics the sample was split into these categories. According to Kendzierski's (1988) method, an individual was classed as a healthy eater schematic if they rated two or more of the three statements between 8 and 11 on both self-descriptiveness and importance; otherwise, the individual was classified as a non-schematic.

\section{Results}

\section{Descriptive Statistics}

The sample consisted of 209 students from a range of disciplines enrolled in a first year psychology course; $75.1 \%$ were female and $24.9 \%$ were male. Approximately $50 \%$ identified themselves as Australian, 33\% as Asian/Asian-Australian, 11\% as European and $6 \%$ as 'other'. The majority of participants lived at home with their parents $68 \%$, while $16 \%$ lived in rental property, $7 \%$ lived in university colleges, $5 \%$ owned their own property.

On average participants in this sample consumed 4.96 servings of $\mathrm{F} \& \mathrm{~V}$ a day $(S D$ $=1.95)$. Given that the recommendations are to consume five servings of vegetables and two servings of fruit a day the majority of the sample did not meet dietary guidelines. Using seven servings as a marker, $87.6 \%(n=183)$ did not consume the recommended daily intake of F\&V. Using Kendzierski and Costello's (2004) Healthy Eater Self-schema scale, participants were categorised as either schematics $48.3 \%(n=101)$ or non- 
schematics $51.7 \%(n=108)$. As expected, schematics had significantly higher intention to consume $\mathrm{F} \& \mathrm{~V}\left(F_{1,208}=59.53, p<.01\right)$ and consumed 1.21 more servings of $\mathrm{F} \& \mathrm{~V}$ per day than non-schematics $\left(F_{1,208}=22.05, p<.01\right)$.

The Pearson product correlation matrix of all variables is presented in Table 1.

Insert Table 1 here

\section{Healthy eater self-schema as a moderator of F\&V consumption}

To address the hypotheses that self-schema will account for a significant amount of variance in $\mathrm{F} \& \mathrm{~V}$ consumption and will moderate the intention-behaviour gap while controlling for past behaviour, a four step hierarchical regression analysis was performed. In accordance with the guidelines specified by Keith (2006), the continuous variables intention, past behaviour and healthy-eater self-schema were mean centred before being entered consecutively into the regression. The product of mean centred intentions and selfschema was entered last. As expected from the TPB, intention was a significant predictor of F\&V consumption $\left(R^{2}=.11, F_{1,207}=24.63, p<.01\right)$. Past behaviour did not account for a significant amount of extra variance in $\mathrm{F} \& \mathrm{~V}$ consumption $\left(\Delta R^{2}=.01, F_{1,206}=3.10, p\right.$ $=.08)$. Self-schema explained a further $2.4 \%$ of variance in $\mathrm{F} \& \mathrm{~V}$ consumption over and above intention and past behaviour $\left(F_{1,205}=5.70, p=.02\right)$. However, the second hypothesis was not supported as healthy eater self-schema did not moderate the intentionbehaviour gap $\left(\Delta R^{2}=.00, F_{1,204}=.12, p=.73\right.$; see Table 2$)$. Insert Table 2 here.

\section{Role of Habit and Self-regulation in Schematics and Non-schematics}

In order to examine the influence of habit and self-regulatory ability on F\&V consumption in schematics and non-schematics the data file was split into schematics $(n=101)$ and non-schematics $(n=108)$ and analysed separately. Significant differences were found between scores on the IGT $\left(F_{1,208}=5.25, p=.02\right)$ such that those with a healthy eater self- 
schema were left with $\$ 200$ more on average than those without a healthy eater selfschema indicating that schematics had superior self-regulatory capacity, specifically they had greater cognitive flexibility and made less risky decisions. No significant differences were found on $\mathrm{TOH}$ measures; however, pre-planning time did approach significance where, contrary to what was expected, non-schematics spent more time pre-planning. Comparing the means of schematics $(M=4.88, S D=1.31)$ to non-schematics $(M=3.39$, $\mathrm{SD}=1.32$ ) on the SRHI revealed significant differences between the two groups such that $\mathrm{F} \& \mathrm{~V}$ consumption habits were greater in schematics than non-schematics $\left(F_{1,207}=66.62\right.$, $p<.01 ;$ see Table 3).

Insert Table 3 here

Intention, habit scores, IGT scores and TOH scores were all mean centred as they were originally continuous variables and multiplied with intention to form moderator variables. Identical hierarchical regression analyses were conducted on both groups where intention was entered first followed by past behaviour in order to control for this variable. Scores on the IGT, two TOH measures and habit were then added in consecutive steps followed by the interaction terms also in separate steps.

The final step of the analysis for non-schematics is presented in Table 4. For this group scores on the IGT accounted for an extra $5.7 \%$ of variance in F\&V consumption $\left(F_{1,103}=4.21, p<.01\right)$, however, scores on the IGT did not moderate the intentionbehaviour gap for non-schematics as they only accounted for an extra $0.4 \%$ of variance, which was not significant $\left(F_{1,99}=.50, p=.48\right)$. TOH scores and the interaction between these variables and intention did not account for any additional variance in $\mathrm{F} \& \mathrm{~V}$ consumption for non-schematics. While habit was not found to account for any additional variance in $\mathrm{F} \& \mathrm{~V}$ consumption $\left(\Delta R^{2}=.03, F_{1,104}=3.32, p=.07\right)$, habit was found to moderate the intention-behaviour gap for non-schematics accounting for an additional 
$5.2 \%$ of variance in $\mathrm{F} \& \mathrm{~V}$ consumption $\left(F_{1,100}=6.52, p=.01\right)$. Figure 1 displays the moderating effect of habit on $\mathrm{F} \& \mathrm{~V}$ consumption in non-schematics.

Insert Table 4 here

Insert Figure 1 here

For schematics, scores on the IGT accounted for an extra $9.1 \%$ of variance in $\mathrm{F} \& \mathrm{~V}$ consumption $\left(F_{1,96}=10.32, p<.01\right)$, while habit only accounted for an additional $.1 \%$ of variance in $\mathrm{F} \& \mathrm{~V}$ consumption $\left(F_{1,97}=.09, p=.76\right)$. Consistent with the final hypothesis, in contrast to non-schematics self-regulatory ability was a moderator of the intention-behaviour gap accounting for an extra $3.8 \%$ of variance in $\mathrm{F} \& \mathrm{~V}$ consumption $\left(F_{1,92}=4.55, p=.04\right)$. Also in contrast to non-schematics, habit was not found to moderate the intention-behaviour gap for schematics accounting for only an additional $1.8 \%$ of variance in $\mathrm{F} \& \mathrm{~V}$ consumption $\left(F_{1,93}=2.10, p=.15\right.$; see table 5$)$. Figure 2 displays the moderating effect of self-regulatory ability on $\mathrm{F} \& \mathrm{~V}$ consumption in schematics. $\mathrm{TOH}$ scores and the interaction between these variables and intention did not account for any additional variance in $\mathrm{F} \& \mathrm{~V}$ consumption for schematics.

Insert Table 5 here

Insert Figure 2 here

\section{Discussion}

The aim of the present research was to examine self-schema as a moderator of intention and behaviour in the domain of $\mathrm{F} \& \mathrm{~V}$ consumption and to investigate the underlying processes that influence this relationship by comparing self-regulation and habit in schematics and non-schematics. While healthy eater self-schema accounted for a significant amount of variance in F\&V consumption, it did not moderate the intention- 
behaviour relationship. However, support was found for the hypothesis that the influence of self-regulation and habit on the intention-behaviour gap differs according to whether one has a healthy eater self-schema.

\section{TPB}

Concerning the prediction of behaviour, intention to consume $\mathrm{F} \& \mathrm{~V}$ accounted for $11 \%$ of variance in behaviour. This was a relatively low amount of accounted for variance compared to other studies which applied the TPB to F\&V consumption, such as Conner, Norman and Bell (2002) who found that intention alone accounted for $30 \%$ of the variance in behaviour. The poor prediction of behaviour may reflect the lack of correspondence between intention and behaviour measures. However, the Block food frequency questionnaire was a validated questionnaire (Block, et al., 2000) and a more accurate and comprehensive means of indexing $\mathrm{F} \& \mathrm{~V}$ consumption than simply asking participants to report how many servings of $\mathrm{F} \& \mathrm{~V}$ they consumed over the last week. Further, several studies utilising the TPB to predict F\&V consumption employed a similar food frequency questionnaire (e.g. Bogers, Brug, Van Assema, \& Dagnelie, 2004; Brug, de Vet, de Nooijer, \& Verplanken, 2006) and obtained meaningful results.

\section{Self-schema}

The imperfect relationship between intention and behaviour epitomises the common observation that people often fail to act on their intentions (Hall \& Fong, 2007). The addition of self-schema explained a further $2 \%$ of variance in $\mathrm{F} \& \mathrm{~V}$ consumption after taking into account intention, indicating that if the person finds healthy eating to be selfdescriptive and important they are more likely to both intend to consume $\mathrm{F} \& \mathrm{~V}$ and to actually consume F\&V. This is comparable to Banting, Dimmock \& Lay (2009) who found that self-schema accounted for an additional $4 \%$ of the variance in exercise behaviour. However, self-schema did not moderate the intention-behaviour gap. These results are again similar to those obtained by Banting et al. (2009) who also found no 
evidence for self-schema as a moderator of intention and behaviour. The non-significant result may be due to the nature of moderator effects, which are sensitive to intercorrelations between variables (McClelland \& Judd, 1993).

Further, it is possible that the rating of scores for healthy eater self-schema and F\&V intentions was subject to reporting bias. Participants who reported high scores for self-schema may have been inclined to report greater intentions to consume $\mathrm{F} \& \mathrm{~V}$ in order to validate their schema rating (Festinger, 1957). Additionally, given that $\mathrm{F} \& \mathrm{~V}$ consumption is considered to be a valuable behaviour, individuals may have overestimated their intention to perform such behaviours as well as their actual execution (Kendzierski \& Costello, 2004). These biases may have confounded the results leading to the finding that self-schema does not moderate the intention-behaviour gap. Future research is needed to determine whether this is the case.

\section{Underlying processes}

Although having a self-schema did not moderate the intention-behaviour gap, once the sample was separated into schematics and non-schematics, results showed that different variables were responsible for the behaviour in each group. In general, it appears that within non-schematics habit is a useful indicator of how intention is translated into action, while within schematics self-regulation appears to be more informative. These results correspond with Hall and Fong's (2007) Temporal Self-regulation Theory which argues that the temporal contingencies of a behaviour influence its performance. As F\&V consumption is a behaviour in which the costs are more proximal than the benefits the value of the benefit is lessened due to the delay in its occurrence. As such the performance of this behaviour is not only influenced by intention but self-regulatory ability and habit strength. The present research sheds light on the role of these variables indicating that their influence differs according to the relevance of the behaviour to the individual; namely, whether one has a healthy eater self-schema. 


\section{Non-schematics}

Within non-schematics habit was found to moderate the intention-behaviour gap, which explained $22 \%$ of the variance in $\mathrm{F} \& \mathrm{~V}$ consumption. The results indicated that an individual who did not perceive healthy eating to be important or self-descriptive and who did not intend to consume $\mathrm{F} \& \mathrm{~V}$ was more likely to translate intention into action if they had previously formed a strong habit. For those who strongly intended to consume F\&V, behaviour was not influenced by the strength of $\mathrm{F} \& \mathrm{~V}$ habits. These results are similar to those found by de Bruijn, et al. (2007) who examined the role of habit on fruit consumption intentions and behaviour and found that intention was a significant predictor of fruit consumption in the low and medium habit groups but was not a significant predictor of fruit consumption in the high habit group.

According to Ouellette and Wood (1998), behaviour that is performed repeatedly and consistently in the presence of particular environmental cues will gradually come to be initiated by those cues without intention formation. This implies that $\mathrm{F} \& \mathrm{~V}$ consumption, within individuals who have high habit strength, is determined by external stimuli rather than intention. In contrast, when a habit has not formed, due to infrequent or inconsistent performance of the behaviour (Verplanken \& Orbell, 2003), intentions are likely to guide $\mathrm{F} \& \mathrm{~V}$ consumption.

\section{Schematics}

Using scores on the IGT as a measure of self-regulation, it was found that within schematics self-regulatory ability moderated the intention-behaviour gap, which explained $24 \%$ of the variance in $\mathrm{F} \& \mathrm{~V}$ consumption. These findings indicate that among schematics with low intentions, self-regulatory ability did not increase the likelihood that F\&V would be consumed. However, among schematics with high intentions, those who also exhibited high self-regulatory ability consumed more $\mathrm{F} \& \mathrm{~V}$, while those with low selfregulatory ability consumed less. These findings clarify previous research on self- 
regulation and the TPB (Allan, Johnston, \& Campbell, in press; Mullan \& Wong, 2009) by demonstrating that the intention-behaviour gap can be reduced when self-regulatory effort is taken into account, but only within certain individuals.

Behaviours such as F\&V consumption, which have a reduced likelihood of performance due to the effort required to execute intentions, have been labelled costly health behaviours (Kendzierski \& Costello, 2004). Kendzierski and Whitaker (1997) suggest that the disincentive of costly health behaviours can be overcome if one has a relevant self-schema. While the current study did not support this assertion, as self-schema did not moderate the intention-behaviour gap, the finding that schematics were more likely to carry out their intentions if their self-regulatory ability was high was consistent with Temporal Self-regulation Theory (Hall \& Fong, 2007). In the case of F\&V consumption, self-regulatory effort may be required to manage time effectively, in order to purchase and prepare healthy foods, and to maintain focus, given that the health benefits of $F \& V$ consumption are not gained immediately and repeated performance of the behaviour is required (Hall \& Fong, 2007).

The specific facets of self-regulation found to be influential in intention-behaviour translation in schematics was cognitive flexibility and cognitive inhibition. Cognitive flexibility may be needed to evaluate and consider the benefits and costs of particular foods when deciding what to purchase and later eat. Cognitive inhibition may be needed to refrain from responding to negative stimuli such as non-nutritious fast food or high caloric snacks (Allan, Johnston, \& Campbell, 2010). These results are comparable to a longitudinal study which examined the role of cognitive inhibition and implicit preference for snack food and found that those with strong implicit preferences for snack foods and low inhibitory capacity gained the most weight (Nederkoorn, Houben, Hofmann, Roefs, \& Jansen, 2010). Future research may benefit from a longitudinal approach which examines whether these results differ within schematics and non-schematics. 
In addition to cognitive flexibility and cognitive inhibition, planning was also measured. While this process was not found to account for any extra variance in $\mathrm{F} \& \mathrm{~V}$ consumption, the difference in scores between schematics and non-schematics approached significance; however, the direction of the results was contrary to what was expected. Non-schematics appeared to spend more time in pre-planning than schematics. This was contrary to what was expected as healthy eater schematics engaged in more F\&V consumption behaviour which involves a considerable amount of preparation and forethought. It is possible that conceptualising planning as an ability, rather than simply determining if one makes a plan, was not a useful measure. However, previous studies examining planning as an ability have found a moderating effect such that 'good planners' produced more effective plans leading to greater consumption of F\&V (Sniehotta, et al., 2006). In regards to methodological concerns, the TOH task employed in this study did not replicate the tasks used by Allan, et al. (in press) or Wong and Mullan (2009) who found significant results, thus this particular task may not have accurately measured planning. Future research to investigate these points is recommended.

\section{Limitations and Methodological Issues}

The first limitation is the reliance on self-report measures. These measures may be subject to impression management, the participants' tendency to self-validate and memory biases (Murdock, 1962). However, participants were only required to recall behaviour over a period of one week, thus the results of this study should be minimally affected by recall bias.

Additionally, the role of self-regulation may differ over an extended time frame such that intention may eventually negate the effects of self-regulation, or alternatively, individual differences in self-regulation may explain more variance in behaviour over a longer period of time (Hall, et al., 2008) and these issues may be resolved in future studies that use a longitudinal approach. Another limitation concerning the measurement of self- 
regulation is that there is no consensus as to how executive function is divided into separate components and what constructs the tests actually measure (Suchy, 2009). In order to use these tests as a means of identifying individual differences that affect behaviour, more research is necessary.

\section{Practical Implications}

The results of the current study can be applied to the design of interventions aimed at increasing the frequency of $F \& V$ consumption. Specifically, the results indicated that different individuals, namely schematics and non-schematics, may benefit from different dietary counselling strategies. The finding that non-schematics are more influenced by habit suggests that their behaviour is under external control. Even though those with higher habit consumed more $\mathrm{F} \& \mathrm{~V}$, these eating habits will not persist if external circumstances change (Danner, et al., 2008). Interventions, such as implementation intentions, which prepare for varying conditions (Gollwitzer, 1999) may be beneficial to these individuals.

Within individuals who consider healthy eating to be important and selfdescriptive, yet continue to experience difficulty consuming the recommended $F \& V$, interventions that emphasise this inconsistency may be beneficial. If an individual is made aware that they have freely chosen to perform in a manner that challenges their selfconcept, they will experience unease and attempt to calibrate their behaviour with their self-concept (Chatzisarantis, et al., 2008). Interventions which use this strategy could engage the individual in the creation of nutritional goals and encourage self-monitoring to ensure that any inconsistencies between intention and action are detected (Kendzierski \& Costello, 2004). Within schematics the role of self-regulation was important in the prediction of $F \& V$ consumption. Self-regulatory ability has been demonstrated to improve over time with repeated exercises of self-control (Baumeister, et al., 2007), thus, behavioural interventions which practice restraint may be beneficial. Additionally, Hall 
and Fong (2007) suggest that the ability to self-regulate is particularly important in western society as the environment is often structured in a manner that promotes unhealthy food choice. As self-regulation is a limited resource (Baumeister, et al., 2007), restructuring the environment to reduce the need for self-regulation may allow efforts to be focused on successfully performing health enhancing behaviours such as F\&V consumption. Thus, health promoters should aim to make healthy options more convenient and unhealthy choices more inconvenient to reduce demands on self-regulatory capacity.

\section{Conclusion}

While self-schema did not affect the relationship between intention and behaviour, when the results were examined based on the self-schema categories it was revealed that within those who find healthy eating important and self-descriptive self-regulation is an important moderator of intention and behaviour, while within those who do not find healthy eating important and self-descriptive habit strength influences the intentionbehaviour relationship. Given that $\mathrm{F} \& \mathrm{~V}$ consumption is associated with the prevention of obesity, heart disease and cancer, failure to eat the recommended intake of $F \& V$ is a significant health concern. Thus, these results are not only valuable for understanding why certain individuals are able to translate their intentions into action, but are also useful in the design of interventions aimed at increasing F\&V consumption.

\section{References}

Ajzen, I. (1991). The theory of planned behavior. Organizational behavior and human decision processes, 50(2), 179-211.

Ajzen, I. (2002). Constructing a TPB questionnaire: Conceptual and methodological considerations. http://people.umass.edu.ajzen/pdf/tpb.measurement.pdf Retrieved 23rd March 2010 
Allan, J., Johnston, M., \& Campbell, N. (in press). Missed by an inch or a mile? Predicting size of intention-behaviour gap from measures of executive control. Psychology \& Health.

Allan, J. L., Johnston, M., \& Campbell, N. (2010). Unintentional eating. What determines goal-incongruent chocolate consumption? Appetite, 54(2), 422-425.

Armitage, C., \& Conner, M. (2001). Efficacy of the theory of planned behaviour: A metaanalytic review. British Journal of Social Psychology, 40(4), 471-499.

Australian Bureau of Statistics. (2009). National Health Survey: Summary of results, Australia 2007-2008. Canberra: ABS.

Banting, L., Dimmock, J., \& Lay, B. (2009). The role of implicit and explicit components of exerciser self-schema in the prediction of exercise behaviour. Psychology of Sport \& Exercise, 10(1), 80-86.

Bargh, J. (1982). Attention and automaticity in the processing of self-relevant information. Journal of Personality and Social Psychology, 43(3), 425-436.

Baumeister, R. F., Schmeichel, B. J., \& Vohs, K. D. (2007). Self-regulation and the executive function: The self as controlling agent. In A. W. Kruglanski \& E. T. Higgins (Eds.), Social psychology: Handbook of basic principles (2nd ed., pp. 516539). New York, NY: Guilford Press.

Block, G., Gillespie, C., Rosenbaum, E., \& Jenson, C. (2000). A rapid food screener to assess fat and fruit and vegetable intake. American Journal of Preventive Medicine, 18(4), 284-288.

Block, G., Hartman, A. M., Dresser, C. M., Carroll, M. D., Gannon, J., \& Gardner, L. (1986). A data-based approach to diet questionnaire design and testing. American Journal of Epidemiology, 124(3), 453. 
Bogers, R., Brug, J., Van Assema, P., \& Dagnelie, P. (2004). Explaining fruit and vegetable consumption: the theory of planned behaviour and misconception of personal intake levels. Appetite, 42(2), 157-166.

Brug, J., de Vet, E., de Nooijer, J., \& Verplanken, B. (2006). Predicting fruit consumption: Cognitions, intention, and habits. Journal of Nutrition Education and Behavior, $38(2), 73-81$.

Chatzisarantis, N., Hagger, M., \& Wang, J. (2008). An Experimental Test of Cognitive Dissonance Theory in the Domain of Physical Exercise. Journal of Applied Sport Psychology, 20(1), 97-115.

Conner, M., Norman, P., \& Bell, R. (2002). The theory of planned behavior and healthy eating. Health Psychol, 21(2), 194-201.

Cross, S., \& Markus, H. (1990). The willful self. Personality and Social Psychology Bulletin, 16(4), 726.

Danner, U., Aarts, H., \& de Vries, N. (2008). Habit vs. intention in the prediction of future behaviour: The role of frequency, context stability and mental accessibility of past behaviour. British Journal of Social Psychology, 47(2), 245-265.

de Bruijn, G. (2010). Understanding college students' fruit consumption. Integrating habit strength in the theory of planned behaviour. Appetite, 54(1), 16-22.

de Bruijn, G., Kremers, S., Vet, E., Nooijer, J., Mechelen, W., \& Brug, J. (2007). Does habit strength moderate the intention-behaviour relationship in the TPB? The case of fruit consumption. Psychology \& Health, 22(8), 899-916.

Festinger, L. (1957). A theory of cognitive dissonance: Stanford University Press. Gollwitzer, P. (1999). Implementation intentions: Strong effects of simple plans. American Psychologist, 54(7), 493-503.

Hall, P., \& Fong, G. (2007). Temporal self-regulation theory: A model for individual health behavior. Health Psychology Review, 1(1), 6-52. 
Hall, P., Fong, G., Epp, L., \& Elias, L. (2008). Executive function moderates the intention-behavior link for physical activity and dietary behavior. Psychology \& Health, 23(3), 309-326.

Humes, G., Welsh, M., Retzlaff, P., \& Cookson, N. (1997). Towers of Hanoi and London: Reliability of two executive function tasks. Assessment, 4(3), 249-257.

Keith, T. (2006). Multiple regression and beyond: Boston: Allyn \& Bacon.

Kendzierski, D. (1988). Self-schemata and exercise. Basic and Applied Social Psychology, $9(1), 45-59$.

Kendzierski, D., \& Costello, M. (2004). Healthy Eating Self-Schema and Nutrition Behavior. Journal of Applied Social Psychology, 34(12), 2437-2451.

Kendzierski, D., \& Whitaker, D. (1997). The role of self-schema in linking intentions with behavior. Personality and Social Psychology Bulletin, 23(2), 139.

Markus, H. (1977). Self-schemata and processing information about the self. Journal of Personality and Social Psychology, 35(2), 63-78.

McClelland, G., \& Judd, C. (1993). Statistical difficulties of detecting interactions and moderator effects. Psychological Bulletin, 114, 376-376.

Mullan, B., \& Wong, C. (2009). Hygienic food handling behaviours. An application of the Theory of Planned Behaviour. Appetite, 52(3), 757-761.

Murdock, B. (1962). The serial position effect of free recall. Journal of Experimental Psychology, 64(5), 482-488.

National Health and Medical Research Council. (2003). Food for health - Dietary guidelines for Australian adults: Australian Government Publishing Service.

Nederkoorn, C., Houben, K., Hofmann, W., Roefs, A., \& Jansen, A. (2010). Control yourself or just eat what you like? Weight gain over a year is predicted by an interactive effect of response inhibition and implicit preference for snack foods. Health Psychology, 29(4), 389. 
Ouellette, J., \& Wood, W. (1998). Habit and intention in everyday life: The multiple processes by which past behavior predicts future behavior. Psychological Bulletin, 124(1), 54-74.

Shallice, T. (1982). Specific impairments of planning. Philosophical Transactions of the Royal Society of London. Series B, Biological Sciences, 298(1089), 199-209.

Sheeran, P., \& Orbell, S. (2000). Self-schemas and the theory of planned behaviour. European Journal of Social Psychology, 30(4), 533-550.

Sniehotta, F., Scholz, U., \& Schwarzer, R. (2005). Bridging the intention-behaviour gap: Planning, self-efficacy, and action control in the adoption and maintenance of physical exercise. Psychology \& Health, 20(2), 143-160.

Sniehotta, F., Scholz, U., \& Schwarzer, R. (2006). Action plans and coping plans for physical exercise: A longitudinal intervention study in cardiac rehabilitation. British Journal of Health Psychology, 11(1), 23-37.

Spiro, R. J., Feltovich, P. J., Jacobson, M. J., \& Coulson, R. L. (1992). Cognitive flexibility, constructivism, and hypertext: Random access instruction for advanced knowledge acquisition in ill-structured domains. Constructivism and the technology of instruction: A conversation, 57-75.

Stein, K. (1995). Schema Model of the Self-Concept. Image: Journal of Nursing Scholarship, 27(3), 187-193.

Subar, A. F., Thompson, F. E., Kipnis, V., Midthune, D., Hurwitz, P., McNutt, S., et al. (2001). Comparative validation of the Block, Willett, and National Cancer Institute food frequency questionnaires. American Journal of Epidemiology, 154(12), 1089. Suchy, Y. (2009). Executive functioning: Overview, assessment, and research issues for non-neuropsychologists. Annals of Behavioral Medicine, 37(2), 106-116. 
Van Duyn, M., \& Pivonka, E. (2000). Overview of the health benefits of fruit and vegetable consumption for the dietetics professional: selected literature. Journal of the American Dietetic Association, 100(12), 1511.

Verplanken, B., Aarts, H., Van Knippenberg, A., \& Moonen, A. (1998). Habit versus planned behaviour: a field experiment. Brit J of Social Psychology, 37(1), 111-128.

Verplanken, B., \& Orbell, S. (2003). Reflections on past behavior: A self-report index of habit strength. Journal of Applied Social Psychology, 33(6), 1313-1330.

Welsh, M., \& Huizinga, M. (2001). The development and preliminary validation of the Tower of Hanoi-revised. Assessment, 8(2), 167.

Wong, C., \& Mullan, B. (2009). Predicting breakfast consumption: An application of the theory of planned behaviour and the investigation of past behaviour and executive function. British Journal of Health Psychology, 14(3), 489-504. 
Table 1. Pearson's product correlation matrix of healthy eater self-schema with TPB, past behaviour, self-regulation and habit measures.

\begin{tabular}{|c|c|c|c|c|c|c|c|c|}
\hline & SS & INT & PB & BEH & HAB & IGT & PPT & ERR \\
\hline SS & - & $.47 * *$ & $.39 * *$ & $.31 * *$ & $.49 * *$ & $.16^{*}$ & -.13 & .11 \\
\hline INT & & - & $.65^{* *}$ & $.33 * *$ & $.69 * *$ & -.06 & .05 & $.21 * *$ \\
\hline PB & & & - & $.30 * *$ & $.62 * *$ & .06 & -.06 & -.03 \\
\hline BEH & & & & - & $.34 * *$ & $.27 * *$ & -.04 & .09 \\
\hline НАВ & & & & & - & -.02 & -.09 & $.15^{*}$ \\
\hline IGT & & & & & & - & -.05 & -.11 \\
\hline PPT & & & & & & & - & .01 \\
\hline ERR & & & & & & & & - \\
\hline
\end{tabular}

Note: $\mathrm{SS}=$ healthy eater self-schema, INT = intention to consume the recommended daily $\mathrm{F} \& \mathrm{~V}, \mathrm{~PB}=$ past behaviour, $\mathrm{BEH}=$ behaviour or $\mathrm{F} \& \mathrm{~V}$ consumption (servings per day), $\mathrm{HAB}=$ self-report habit index score, IGT $=$ final total (.001\$), PPT $=\mathrm{TOH}$ preplanning time (seconds), $\mathrm{ERR}=\mathrm{TOH}$ error. ${ }^{*} p<.01, * p<.05$ (2-tailed). 
Table 2. Final Step of hierarchical regression analysis: intention, past behaviour, self-schema as predictors of $\mathrm{F} \& \mathrm{~V}$ consumption and self-schema as a moderator of intention and behaviour.

\begin{tabular}{llllccc}
\hline Model & Variable & $\boldsymbol{\beta}$ & $\boldsymbol{t}$ & $\boldsymbol{R}^{2}$ & $\boldsymbol{\Delta R}^{2}$ & $\boldsymbol{p}$ \\
\hline Step 4 & INT & .15 & 1.50 & & .14 \\
& PB & .12 & 1.37 & & .17 \\
& SS & .19 & 2.41 & & $.02 *$ \\
& INTxSS & .02 & .34 & .14 & .00 & .73
\end{tabular}

Note: INTxSS = product interaction between intention and healthy eater self-schema, overall $R^{2}$ $=.25, *$ denotes statistical significance at the .05 level. 
Table 3. Group differences on self-regulation measures between healthy eater schematics and non-schematics.

\begin{tabular}{|c|c|c|c|c|c|c|c|c|}
\hline \multirow[b]{2}{*}{ Task } & \multirow[b]{2}{*}{ Measure } & \multicolumn{2}{|c|}{ Schematic } & \multicolumn{2}{|c|}{ Non-schematic } & \multirow[b]{2}{*}{$d f$} & \multirow[b]{2}{*}{$F$} & \multirow[b]{2}{*}{$p$} \\
\hline & & $M$ & Range & $M$ & Range & & & \\
\hline IGT & FT & 1.77 & $.00-3.10$ & 1.57 & $-.05-3.05$ & 207 & 5.25 & $.02 *$ \\
\hline \multirow[t]{2}{*}{ TOH } & PPT & 18.01 & $1.40-111.30$ & 22.76 & $1.18-85.67$ & 207 & 3.55 & .06 \\
\hline & ERR & 33.70 & $7-119$ & 28.67 & $7-101$ & 207 & 2.51 & .12 \\
\hline
\end{tabular}

Note: $\mathrm{FT}=$ final total $(.001 \$),{ }^{*}$ denotes statistical significance at the .05 level. 
Table 4. Final step of hierarchical regression analysis: intention, past behaviour, habit, selfregulation and interactions as predictors of $\mathrm{F} \& \mathrm{~V}$ consumption within non-schematics.

\begin{tabular}{|c|c|c|c|c|c|c|}
\hline Model & Variable & $\beta$ & $t$ & $R^{2}$ & $\Delta R^{2}$ & $p$ \\
\hline \multirow[t]{11}{*}{ Step 10} & INT & -.13 & -.83 & & & .41 \\
\hline & PB & .03 & .27 & & & .79 \\
\hline & HAB & .21 & 1.60 & & & .11 \\
\hline & IGT & .26 & 2.63 & & & $.01 * *$ \\
\hline & PPT & -.26 & -.74 & & & .46 \\
\hline & ERR & -.03 & -.08 & & & .94 \\
\hline & INTxHAB & -.32 & -2.26 & & & $.03^{*}$ \\
\hline & INTxIGT & .08 & .84 & & & .41 \\
\hline & INTxPPT & .35 & 1.00 & & & .32 \\
\hline & INTxERR & .08 & .19 & & & .85 \\
\hline & & & & .22 & .00 & .85 \\
\hline
\end{tabular}

Note: INTxHAB = product interaction between intention and habit, INTxIGT $=$ product interaction between intention and IGT, INTxPPT = product interaction between intention and TOH pre-planning time, INTxERR = product interaction between intention and TOH error score, overall $R^{2}=.22$, ** denotes statistical significance at the .01 level, $*$ denotes statistical significance at the .05 level. 
Table 5. Final step of hierarchical regression analysis: intention, past behaviour, habit, selfregulation and interactions as predictors of $\mathrm{F} \& \mathrm{~V}$ consumption within schematics.

\begin{tabular}{|c|c|c|c|c|c|c|}
\hline Model & Variable & $\beta$ & $t$ & $R^{2}$ & $\Delta R^{2}$ & $p$ \\
\hline \multirow[t]{11}{*}{ Step 10} & INT & .08 & .54 & & & .59 \\
\hline & PB & .09 & .64 & & & .52 \\
\hline & HA В & .15 & 1.02 & & & .31 \\
\hline & IGT & .11 & .83 & & & .41 \\
\hline & PPT & -1.02 & -1.32 & & & .19 \\
\hline & ERR & -.04 & -.09 & & & .93 \\
\hline & INTxHAB & -.13 & -1.01 & & & .32 \\
\hline & INTxIGT & .29 & 2.19 & & & $.03 *$ \\
\hline & INTxPPT & .91 & 1.19 & & & .24 \\
\hline & INTxERR & .11 & .26 & & & .80 \\
\hline & & & & .24 & .00 & .80 \\
\hline
\end{tabular}

Note: overall $R^{2}=.24$, * denotes statistical significance at the .05 level. 


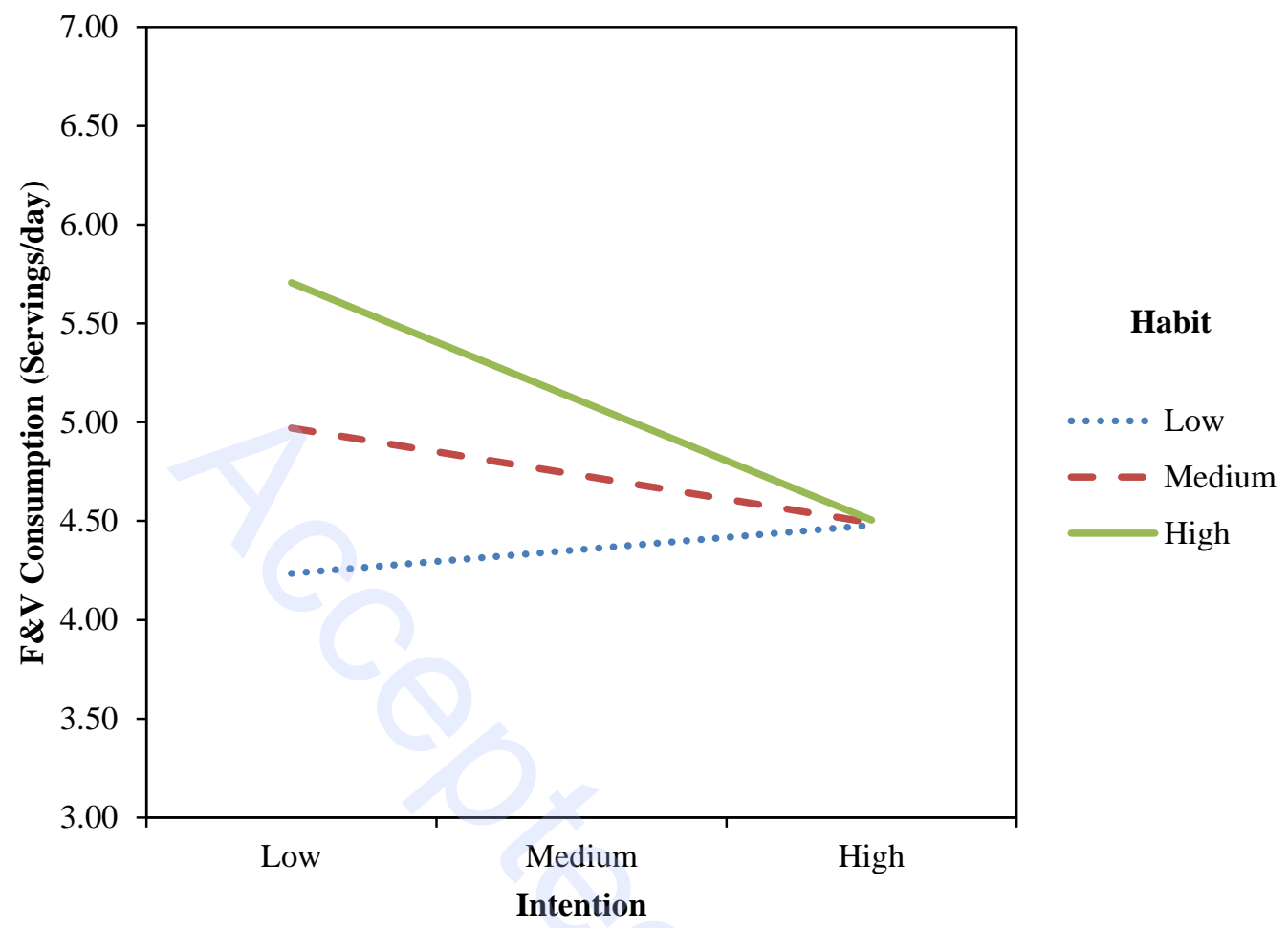




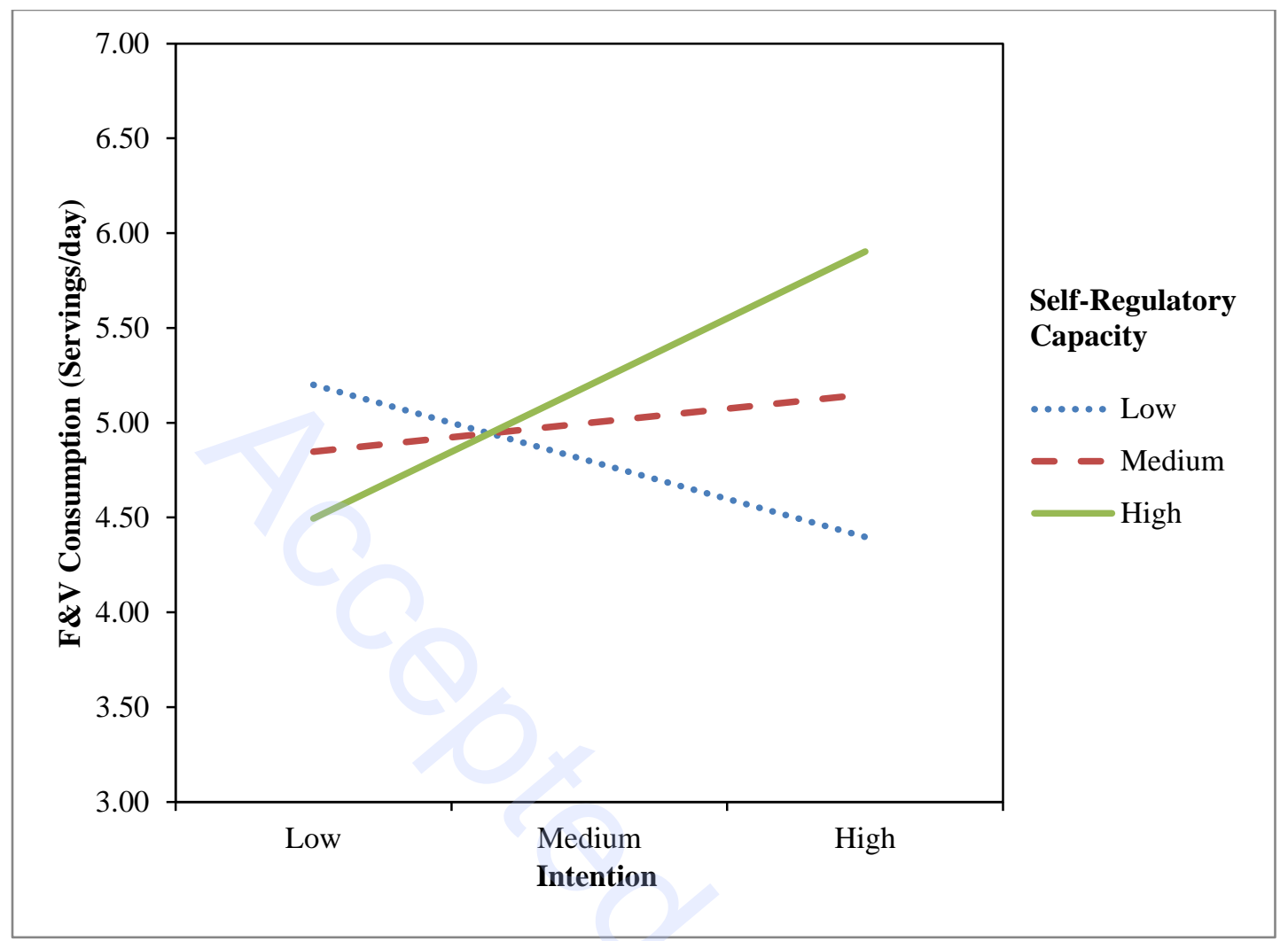




\section{Figure Captions}

Figure 1. Moderating effect of habit on the intention-behaviour gap within non-schematics.

Figure 2. Moderating effect of self-regulatory ability on the intention-behaviour gap within schematics. 